\title{
Effect of Acid and Alkaline Environment on Dynamic Strength and Porosity Characteristics of Bursting Liability Coal
}

\author{
Lei Li, ${ }^{1}$ Jiangbo Fan $\mathbb{D}^{2},{ }^{2}$ Ningning Liu, ${ }^{1}$ Shuang Gong $\mathbb{D},{ }^{3,4}$ and Daming Yang ${ }^{5}$ \\ ${ }^{1}$ China Coal Technology and Engineering Group Energy Development Co., Ltd., Beijing, China \\ ${ }^{2}$ China Coal Technology and Engineering Group Energy Investment Qinhuangdao Co., Ltd., Qinhuangdao, China \\ ${ }^{3}$ School of Energy Science and Engineering, Henan Polytechnic University, Jiaozuo 454000, China \\ ${ }^{4}$ Henan Key Laboratory for Green and Efficient Mining \& Comprehensive Utilization of Mineral Resources, \\ Jiaozuo 454000, China \\ ${ }^{5}$ School of Mining and Geomatics Engineering, Hebei University of Engineering, Handan 056038, China
}

Correspondence should be addressed to Jiangbo Fan; 88161302@qq.com

Received 3 June 2021; Accepted 24 July 2021; Published 17 August 2021

Academic Editor: Zonglong Mu

Copyright $\odot 2021$ Lei Li et al. This is an open access article distributed under the Creative Commons Attribution License, which permits unrestricted use, distribution, and reproduction in any medium, provided the original work is properly cited.

In order to investigate the influence of acid and alkaline environment on dynamic strength and porosity characteristics of bursting liability coal, scanning electron microscopy (SEM) and X-ray diffraction (XRD) analysis were used to compare the microstructures of coal with different bursting liabilities. A split Hopkinson bar (SHPB) was used to test the dynamic compressive strength and tensile strength of coal samples with different bursting liabilities. The results show that the surface micromorphology and structure characteristics of coal samples with different bursting liabilities are representatives, which can be used as an auxiliary basis to determine the bursting liability of coal seam. The microstructure of coal with strong bursting liability is characterized by mylonitic, fragmentary, and brecciated structure, and the microstructure is diverse and complex. However, the microstructure of no bursting liability coal is single and uniform. Coal with strong bursting liability shows tensile, compressive, and shear cracks produced by tectonic action, and the distribution of cracks is complicated. The development of fissures is greatly affected by the degree of coal metamorphism, organic components, minerals, and other factors. Under acidic and alkaline environments, the decrease amplitude of tensile strength of coal is obviously larger than that in neutral solution, which indicates that under the action of acid-based solution soaking, the easily soluble minerals in coal react with hydrogen ions and hydroxyl ions in solution obviously. Porosity increment in acidic environment is much larger than that in alkaline and neutral environments. The strong bursting liability coal is more sensitive to acidic environment, while the no bursting liability coal is more sensitive to alkaline environment.

\section{Introduction}

With the development of the technology of hydraulic fracturing and carbon dioxide gas fracturing to extract coalbed methane, the property transformation of coal reservoir and the scope of mining are expanding $[1,2]$. How to use a reasonable fracturing fluid to make the coal reservoir achieve the best fracturing permeability effect has become one of the important issues in the current research of efficient CBM extraction engineering [3, 4]. In addition, the stability of carbon dioxide storage in the deep nonrecoverable coal seam determines the effectiveness of the underground storage technology of carbon dioxide. Previous studies have shown that water in nature is rarely completely neutral, generally (weakly) acidic, or (weakly) alkaline hydrochemical solution [5]. After the rock mass is eroded by the water chemical solution because the water solution takes away part of the cement, the connection between the mineral aggregates is weakened. There are many microcracks and holes in the rock mass, and the porosity increases, which leads to the deterioration of the strength and other macroproperties of the rock mass. This is a threat to the long-term stability of rock engineering. 
In mining engineering, due to long-term precipitation and groundwater supplement, the water stored in the underground reservoir of coal mine may cause the change of acid-base property of water, which will weaken the stability of coal pillar dam structure. Under the action of earthquake or blasting and other dynamic load disturbances, the instability of coal pillar dam structure may be caused [6]. At present, the physical and mechanical properties of coal have been widely studied, such as compressive strength $[7,8]$, tensile strength [9-11], fracture characteristics [12, 13], elastic modulus [14], shear strength [15], and triaxial strength [16]. However, the change of strength characteristics and porosity of coal under the influence of acid-base environment has not been reported. However, this topic not only has an important impact on the efficient extraction of coal seam gas fracturing and underground storage of carbon dioxide but also has an important impact on the stability of the underground reservoir coal pillar dam. Therefore, it is necessary to study the influence of acid-base environment on the strength and porosity of coal.

There are two main branches in the study of water rock interaction: one focuses on the influence of water on rock chemistry and the other focuses on the influence of water on rock physical mechanics. In a broad sense, water rock interaction can be divided into three categories: (1) water rock chemical interaction, including dissolution, hydration, acid-base erosion, chemical precipitation, oxidationreduction, and ion exchange [17]; (2) water rock physical interaction, including lubrication, argillization, softening, drying wetting cycle, and freeze-thaw cycle [18]; and (3) water rock mechanical interaction, mainly including hydrostatic pressure and hydrodynamic pressure [19]. In recent decades, many scholars have performed a lot of meaningful research works on water-rock chemical interaction, mainly focusing on the effect of chemical solution on the macroscopic mechanical properties of rocks. The corrosion mechanism of different chemicals on rocks was compared by Rebinder [20]. Combined with Griffith strength theory, the mechanism of the reduction of mineral surface energy and crack growth caused by the adsorption of chemical substances was discussed. Feucht and Logan [21] carried out triaxial tests on sandstone specimens with prefabricated cracks after soaking in saturated water, sodium chloride solution, calcium chloride solution, and sodium sulfate solution. The influence of hydrochemical solution on the strength of sandstone is analyzed, and the influence of different water solutions on the friction strength and friction factor of precracked sandstone is discussed. Feng et al. [22, 23] studied the fracture characteristics of granite under different aqueous solution environments through the immersion test and fracture test. The time fractal characteristics in the process of stress increase, creep, and relaxation are analyzed. Based on the above analysis, the research on the interaction between water and rock is mainly focused on the simple fitting of macro and microobservation data, and the degradation law of the mechanical parameters of rock samples with the number of dry and wet cycles is obtained. However, there are few literatures on the mechanism of coal deterioration caused by drying and wetting, especially on the impact of acidbase environment on bursting liability coal.

In view of the complexity of the degradation mechanism of coal under the action of dry-wet cycle in acid-base environment, the degradation laws of strength parameters and porosity characteristics of coal under the action of acid-base environment $(\mathrm{pH}=4,7,9)$ and dry-wet cycle $(n=1,3,6,10)$ were studied on the basis of the microtest, dynamic compression, and tensile test of coal. Chemical kinetics and porosity evolution law are used to explain the degradation mechanism of coal with different bursting liabilities.

\section{Test Preparation}

2.1. Specimen Preparation. The coal samples with different bursting liabilities were taken from different coal seams of Qinneng No. 3 Mine, Qinhuangdao City, Hebei Province, China. To study the dynamic compressive and tensile strength of coal samples, cylindrical samples and Brazilian disc samples were made, respectively. In order to simulate the actual situation of natural water solution, referring to Zhang et al. [24], the lower limit of the $\mathrm{pH}$ value under acidic condition is 4 , and the upper limit of the $\mathrm{pH}$ value under alkaline condition is 9. There are three kinds of water retention solutions used: distilled water with $\mathrm{pH}=7$, acid solution with $\mathrm{pH}=4$, and alkaline solution with $\mathrm{pH}=9$. First, the mineral composition of coal samples was tested, and then, the samples were soaked in different $\mathrm{pH}$ values $(\mathrm{pH}=4,7,9)$ for $1,3,6$, and 10 times of dry-wet cycles. After the cycles, the saturated samples and the dry samples dried for $24 \mathrm{~h}$ were subjected to dynamic compression and tensile tests. Finally, the variation of porosity was analyzed.

There are 78 coal samples used for the dynamic uniaxial compression test, which are divided into 13 groups (0-12 groups) with 6 specimens in each group, 3 in each of two categories: strong bursting liability and no bursting liability. Group 0 specimens are the original specimens without wetdry cycling. Groups 1, 2, 3, and 4 specimens are subjected to uniaxial compression tests after $1,3,6$, and 10 wet-dry cycles with soaking solution $\mathrm{pH}=7$. The 5 th, 6 th, 7 th, and 8 th groups of specimens were subjected to uniaxial tests after 1 , 3,6 , and 10 wet-dry cycles with immersed solution $\mathrm{pH}=4$. The 9th, 10th, 11th, and 12th groups of specimens were subjected to uniaxial compression tests after $1,3,6$, and 10 wet and dry cycles with immersed solution of $\mathrm{pH}=9$, respectively.

The saturated water absorption of coal sample is determined by the vacuum pumping method, and the test results are shown in Figure 1. It can be found that the water absorption of coal with strong bursting liability is lower than that of coal with no bursting liability. The water absorption of coal sample is the highest in acid environment with $\mathrm{pH}=4$, followed by alkalinity, and the lowest in neutral environment. The results show that the dissolution effect of acid is the strongest and that of alkaline is greater than that of neutral solution. 


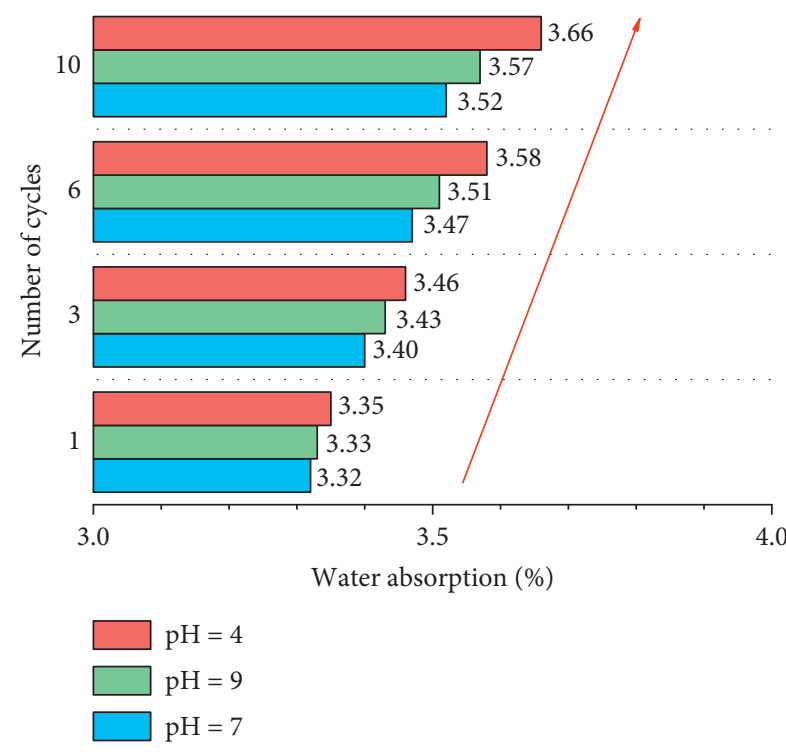

(a)

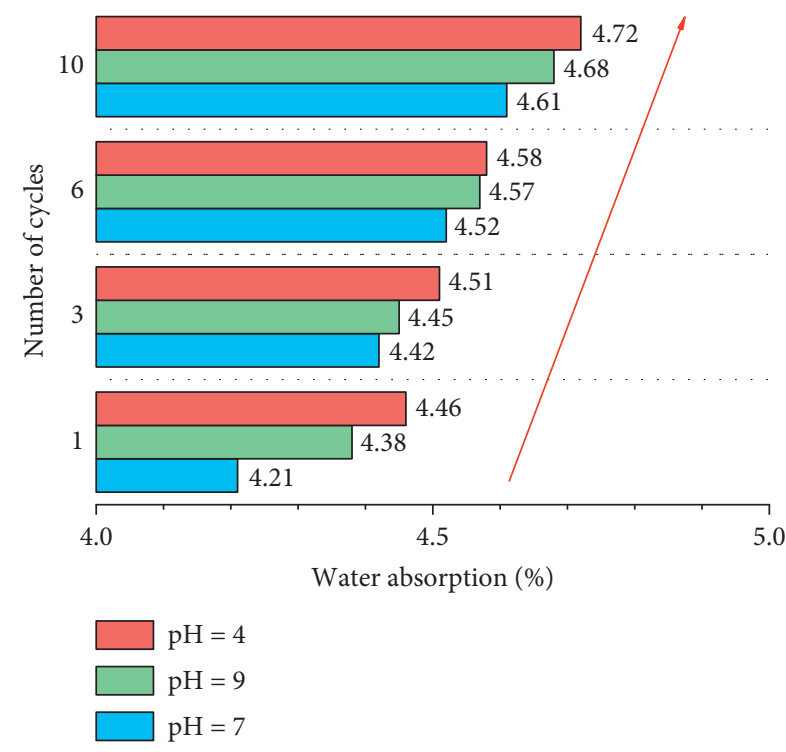

(b)

Figure 1: The relationship between water absorption and cycle times of coal under different acid and alkali environments: (a) strong bursting liability; (b) no bursting liability.

2.2. Experimental System. The loading device for the dynamic mechanical test of coal is a split Hopkinson pressure bar (SHPB) loading system. The SHPB dynamic rock mechanics test system is shown in Figure 2. The Hopkinson rod is made of $35 \mathrm{CrMn}$ steel with a density of $7800 \mathrm{~kg} / \mathrm{m}^{3}$, elastic modulus of $200 \mathrm{GPa}$, and Poisson's ratio of 0.28 . The length and diameter of input and output rods of SHPB loading system are $2 \mathrm{~m}$ and $0.05 \mathrm{~m}$, respectively. A strain gauge is attached to the middle of the input rod and the output rod to record the deformation of the rod. The launching pressure of SHPB loading device is set to $0.50 \mathrm{MPa}$. Figure 3 is the dynamic balance verification of typical coal sample. It can be seen that the force balance is satisfied in the loading process of sample, and the static theory can be used for analysis.

\section{Results and Discussion}

3.1. Microstructure Characteristics of Bursting Liability Coal. Due to the complexity of coal itself and the limitation of research methods, the previous research on the microstructure and macerals of impact prone coal is lack of systematicness. However, in recent years, with the development of X-ray diffraction (XRD) in the basic research of coal composition and structure in coal chemistry, scanning electron microscopy (SEM), and optical electron microscopy observation technology developed in 1980s, it is possible to analyze the microstructure, minerals, and macerals of coal with bursting liability. Therefore, the relationship between the microstructure characteristics and the bursting liability of coal can be systematically analyzed. Figure 4 shows the XRD analysis results of coal samples with different bursting liabilities. It is found that the higher the bursting liability of coal seam, the lower the content of clay minerals; however, the higher the content of amorphous and quartz. Based on the X-ray diffraction spectra, the values of the microcrystalline parameters of the tested coal samples can be calculated according to the relevant equations of coal petrology and coal chemistry, and then, their influence on the bursting liability of coal can be analyzed. The average stacking thickness $L_{\mathrm{c}}$ of the microcrystalline lamellae of the coal sample was chosen as the microcrystalline parameter of the coal, which was calculated as follows:

$$
L_{\mathrm{c}}=\frac{0.94 \lambda}{\beta_{002} \cos \theta_{002}},
$$

where $\lambda$ is the wavelength of $\mathrm{X}$-rays, $\theta_{002}$ is the peak position of peak (002), and $\beta_{002}$ is the full width of half maximum intensity.

The comparative results of XRD microcrystalline parameters of coal samples (Table 1) show that the smaller the average stacking thickness of microcrystalline lamellae, i.e., the smaller the $L_{\mathcal{c}}$, the greater the bursting liability of the coal.

Previous studies on the surface micromorphology of coal have mainly focused on coal with gas outburst category, while SEM studies on the microstructure of bursting liability coal are very few. Therefore, on the basis of the previous study on the microstructure characteristics of coal and gas outburst coal, the surface microstructure of coal with different bursting liabilities was observed by using a scanning electron microscope (SEM) to analyze the surface microstructure characteristics of coal with different bursting liabilities. It is very necessary and beneficial to deeply understand the micromechanism of coal rock dynamic instability and accurately identify the coal seam bursting liability. Figure 5 shows the surface micromorphology of coal samples with different bursting liabilities. The strong bursting liability coal shows scaly and mylonitic microstructure, as shown in Figures 5(a) and 5(b). Mylonitic structure is usually produced after the coal sample loses 


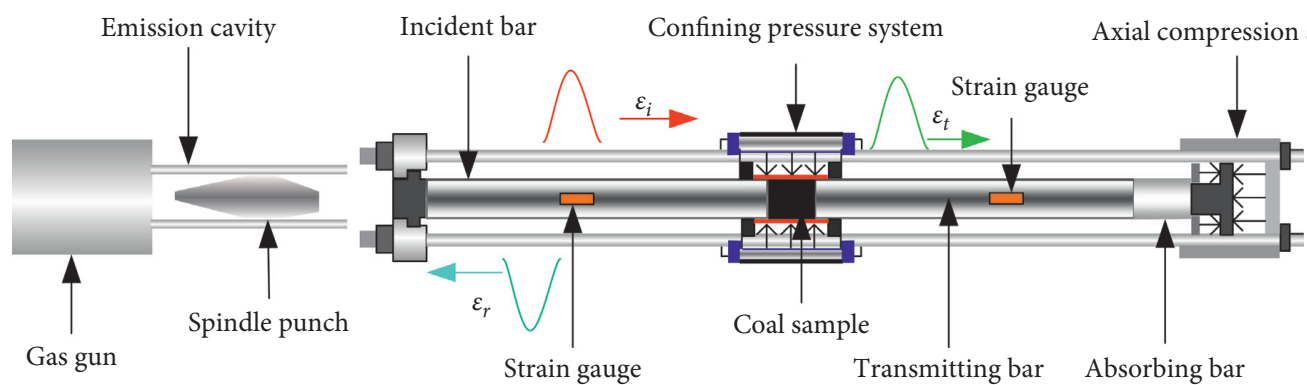

Figure 2: Structure and schematic diagram of the improved SHPB experimental device.

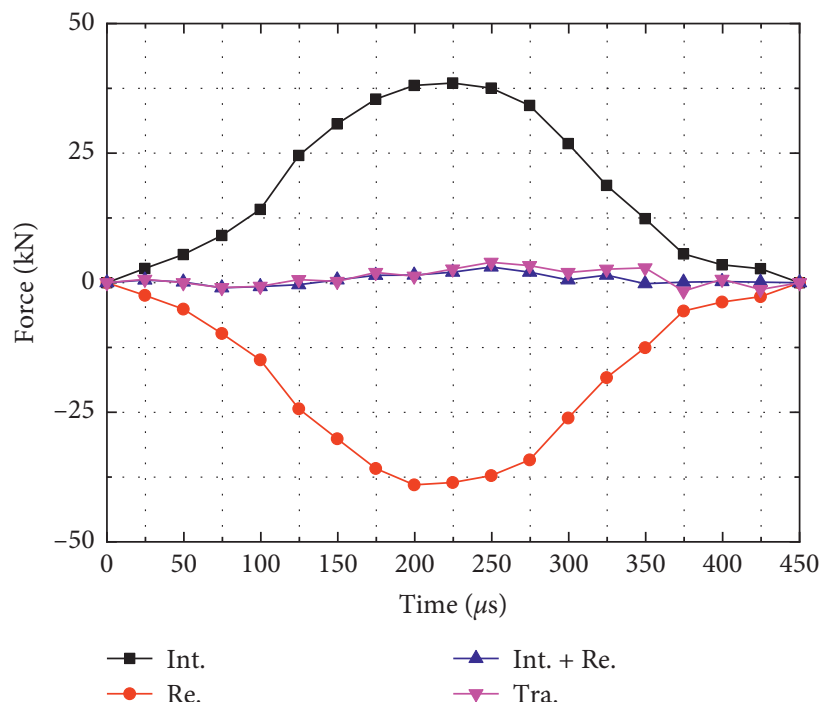

Figure 3: Dynamic force equilibrium.

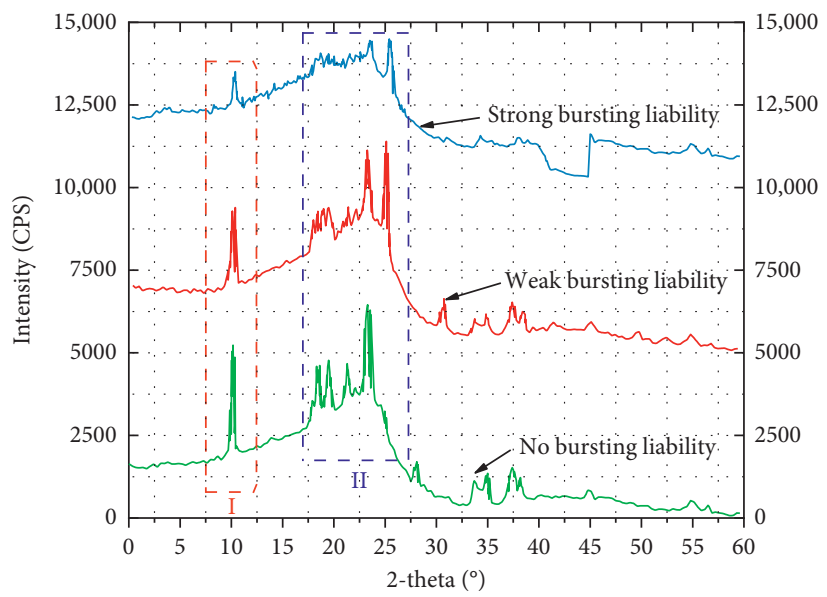

FIgURE 4: XRD analysis results of coal samples with different bursting liabilities.

TABLE 1: Comparison of XRD microcrystalline parameters of coal samples.

\begin{tabular}{|c|c|c|c|c|c|}
\hline Types of coal samples & $2 \theta_{002}\left({ }^{\circ}\right)$ & $\beta_{002}(\mathrm{rad})$ & $2 \theta_{100}\left({ }^{\circ}\right)$ & $\beta_{100}(\mathrm{rad})$ & $L_{\mathrm{c}}(\mathrm{nm})$ \\
\hline Strong bursting liability & 24.1 & 0.176 & 42.9 & 0.312 & 0.868 \\
\hline Weak bursting liability & 23.9 & 0.164 & 45.1 & 0.308 & 0.903 \\
\hline No bursting liability & 23.8 & 0.152 & 44.0 & 0.284 & 0.915 \\
\hline
\end{tabular}




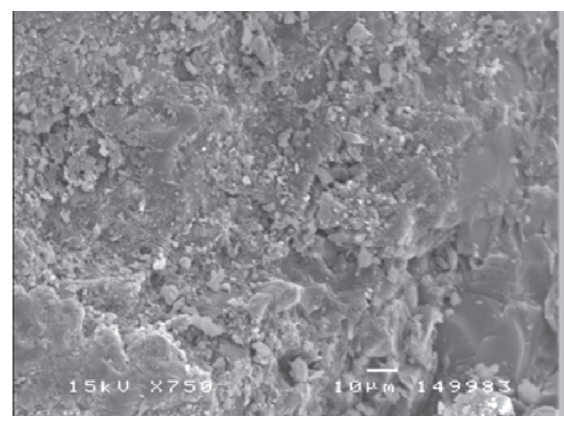

(a)

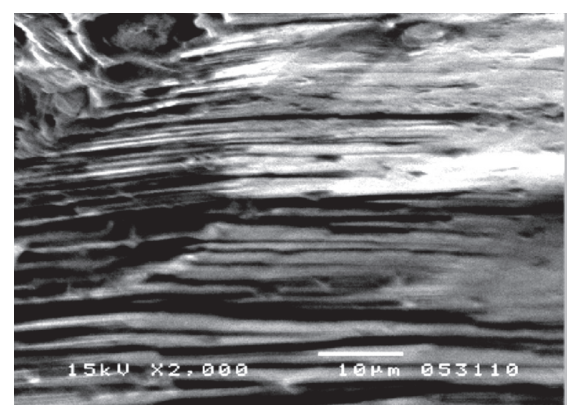

(c)

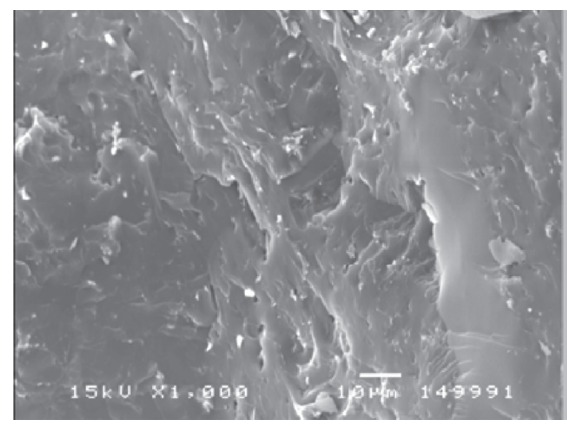

(e)

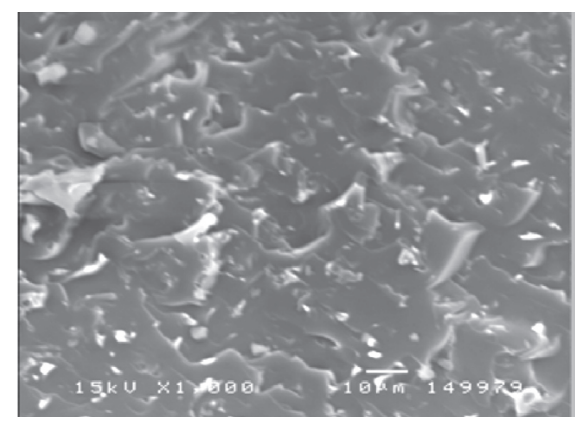

(b)

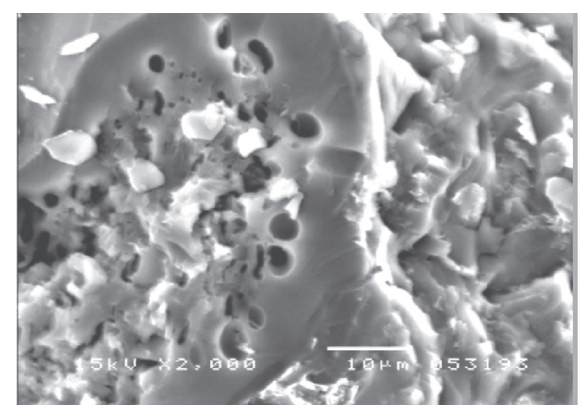

(d)

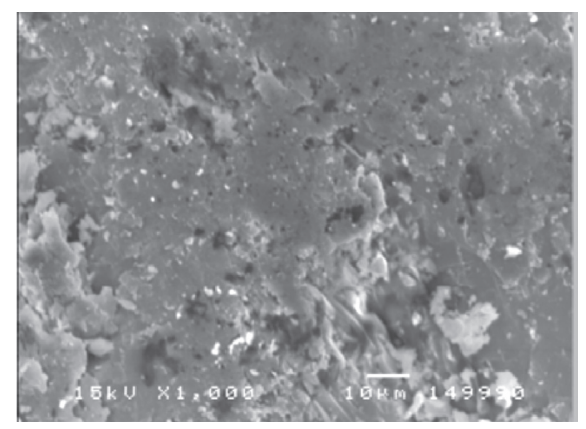

(f)

Figure 5: Surface micromorphology of coal samples with different bursting liabilities: (a), (b) strong bursting liability; (c), (d) weak bursting liability; (e), (f) no bursting liability.

confining pressure, which is also a common microstructure in mylonitic coal. Once the confining pressure of this kind of coal is lost, some of the coal mass will show powder-like, scale-like microstructure. The more the mylonitic structure content in coal, the greater the damage degree of coal mass and the lower the permeability of coal seam. It also shows that under the same geological and stress field conditions, strong bursting liability coal is most prone to sudden failure of coal mass. However, the weak bursting liability coal shows a sheet-like and intergranular porous structure, as shown in Figures 5(c) and 5(d). The no bursting liability coal shows shell-like and porous microstructure, as shown in Figures 5(e) and 5(f).

According to the analysis of surface micromorphology characteristics of coal with different bursting liabilities, the surface micromorphology and structure characteristics of coal samples with different bursting liabilities are representative, which can be used as an auxiliary basis to determine the bursting liability of coal seam. In addition, the microstructure of coal with strong bursting liability is characterized by mylonitic, fragmentary, and brecciated structure, and the microstructure is diverse and complex. However, the microstructure of no bursting liability coal is single and uniform.

The scanning electron microscope (SEM) observation surface is a two-dimensional natural section, which can be used to observe and study the development characteristics of fractures from multiple angles, including fracture properties, size, development background, filling, opening degree, density, and the relationship between fractures and bedding, components, and so on. The SEM observation scale ranges from nanometer to micrometer, including cracks in and between coal matrix blocks. Figure 6 shows the distribution characteristics of fractures on parallel bedding plane of coal samples with different bursting liabilities. It can be found that the fissures in coal with strong bursting liability (Figures 6(a) and 6(b)) show the characteristics of exogenous fissures, which are obviously influenced by geological tectonic stress and mainly consist of compressive, tensile, and shear fissures. Tensile fracture is the result of brittle 


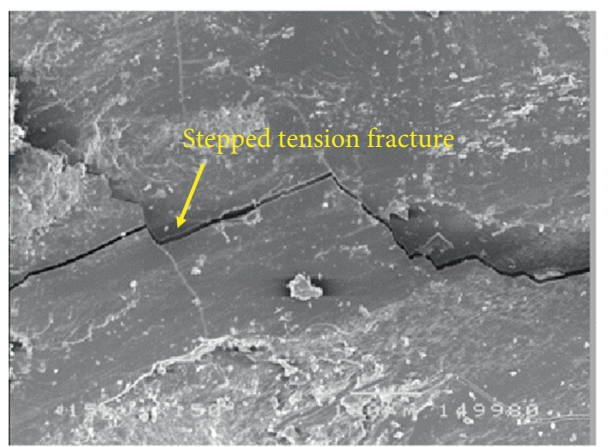

(a)

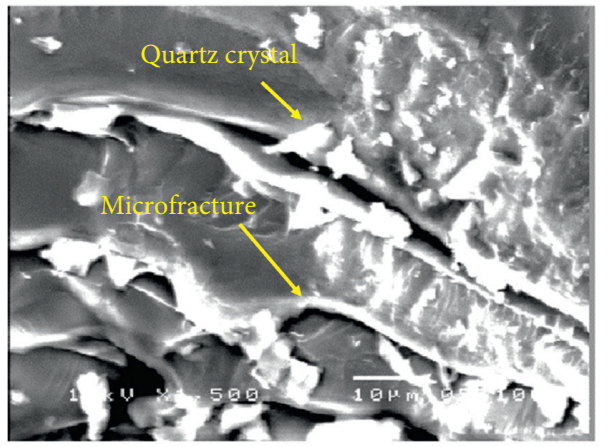

(c)

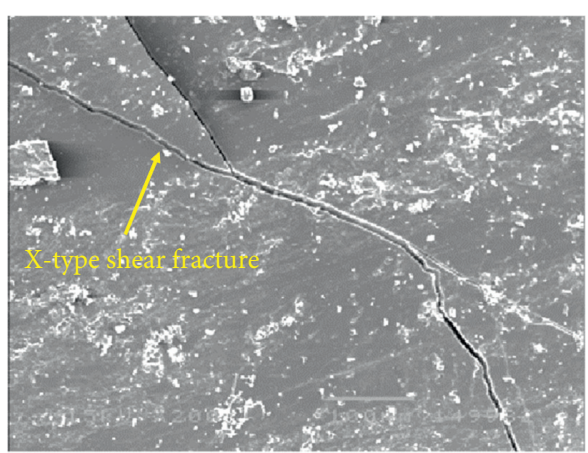

(b)

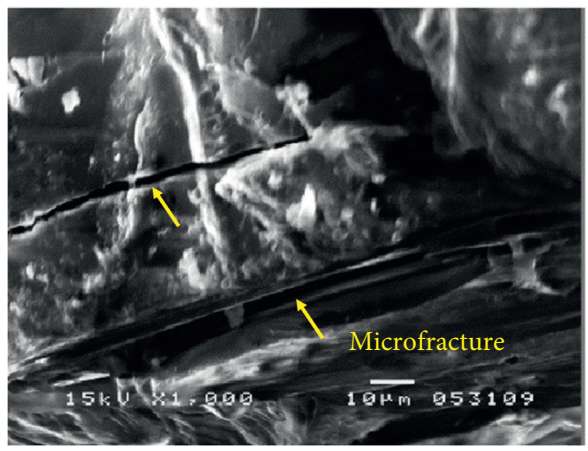

(d)

FIGURE 6: Distribution characteristics of fractures on parallel bedding plane of coal samples with different bursting liabilities: (a), (b) strong bursting liability; (c), (d) no bursting liability.

deformation of coal. In statistics, the directionality of tensional cracks can reflect the characteristics of the regional stress field. Cracks in coal with weak bursting liability appear as $10 \mu \mathrm{m}-30 \mu \mathrm{m}$ microfissure. The connectivity between the cracks is obvious. The morphological characteristics and distribution of microfissures in coal are related to the bursting liability of coal. Coal with strong bursting liability shows tensile, compressive, and shear cracks produced by tectonic action, and the distribution of cracks is complicated. The development of fissures is greatly affected by the degree of coal metamorphism, organic components, minerals, and other factors.

3.2. Acid and Alkaline Environment on Dynamic Strength of Bursting Liability Coal. In order to analyze the influence of acid-base environment on the dynamic strength of coal, the dynamic compression and tensile tests of coal with different bursting liabilities were carried out to test the influence of different $\mathrm{pH}$ values on the strength. The uniaxial stressstrain curves of coal under different acid-base environments and different cycles were obtained by the dynamic uniaxial compression test, as shown in Figure 7.

The total degradation degree calculation formula is defined as

$$
D_{j}=\frac{\left(\sigma_{c 0}-\sigma_{c j}\right)}{\sigma_{c 0} \times 100 \%},
$$

where $\sigma_{c 0}$ is the uniaxial compressive strength of coal without soaking solution, and $\sigma_{c j}$ is the uniaxial compressive strength of the coal soaked for $j$ cycle stage.
Phase average deterioration is defined as

$$
D_{n}=\frac{\left(D_{j}-D_{(j-1)}\right)}{\left(n_{j}-n_{(j-1)}\right)},
$$

where $D_{j}$ is the total deterioration degree of coal after the $j$ cycle stage, and $n_{j}$ is the number of cycles.

According to the test curves in Figure 8, the dynamic uniaxial compressive strength and deterioration degree of coal under different acid-base environments $(\mathrm{pH}=7,9,4)$ and different cycles $(n=1,3,6,10)$ are given in Table 2 .

It can be seen from Table 2 that the total deterioration degree $D_{j}$ increases gradually, which indicates that the damage of coal caused by dry-wet cycle is gradual. In the early stage of dry-wet cycle, the coal is significantly affected, and the average deterioration degree is large. After that, the influence of cyclic action is reduced, and the average degradation degree is small. Under dry condition, the total deterioration of coal with strong bursting liability and no bursting liability in the first stage is $14.790 \%$ and $32.345 \%$ in acid environment $(\mathrm{pH}=4)$, $10.512 \%$ and $18.398 \%$ in the first stage in alkaline environment, and $8.309 \%$ and $10.381 \%$ in neutral environment. It shows that the degradation in acid environment is significantly greater than that in neutral and alkaline environment. In the saturated state, the deterioration degree of coal increases obviously, which is due to the existence of water in the coal rock, resulting in the sharp decrease of coal strength.

A total of 78 Brazilian splitting test specimens were divided into 13 groups, with a total of 10 specimens in each group, including 3 specimens in two states of dry and 


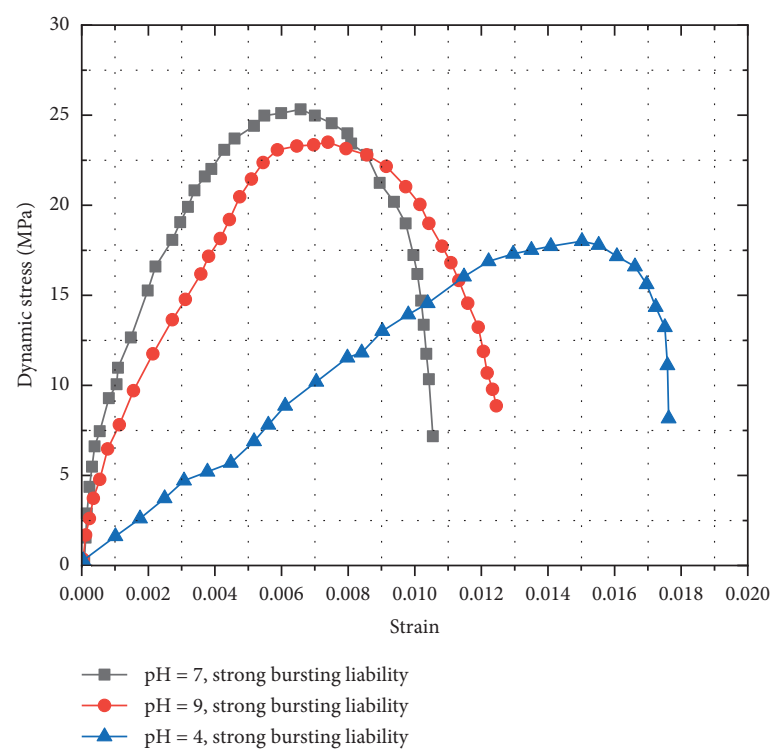

(a)

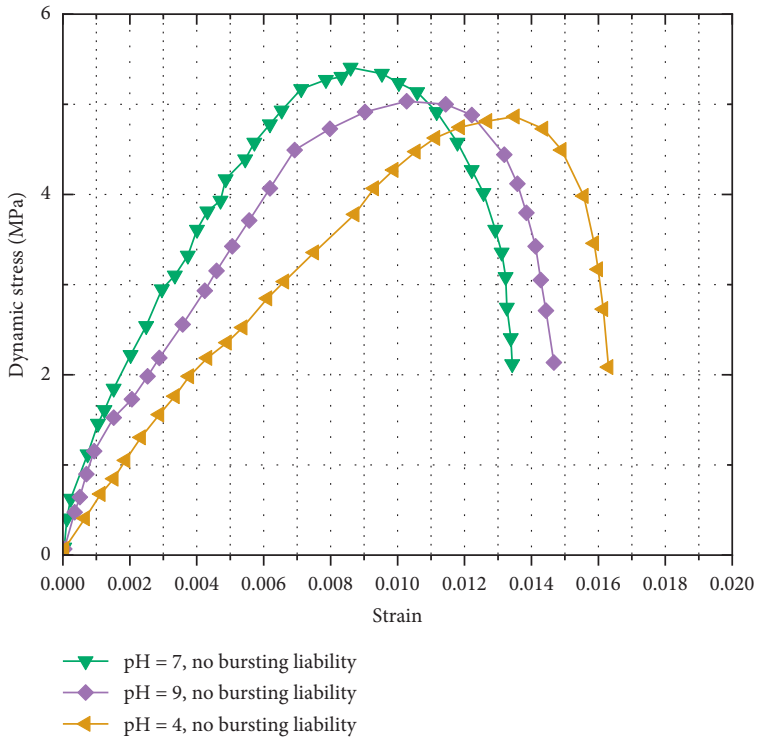

(b)

FIgURe 7: Dynamic stress-strain curve of coal specimen with different bursting liabilities under acid-base environment. (a) Strong bursting liability. (b) No bursting liability.

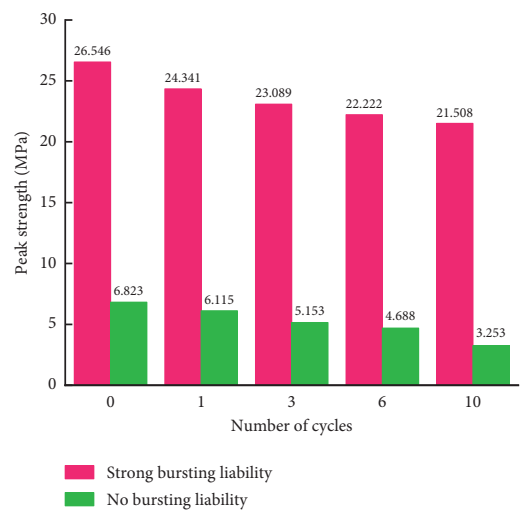

(a)

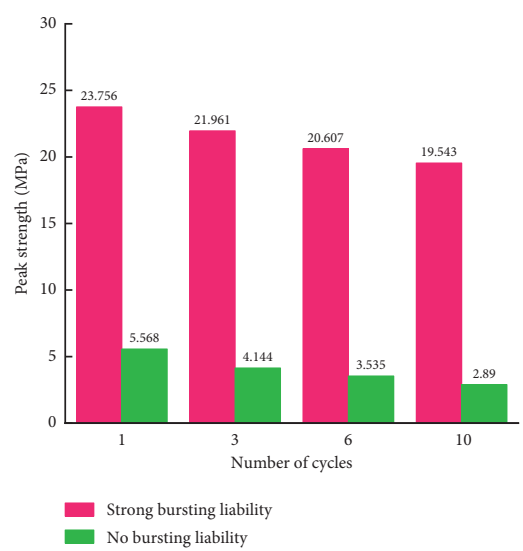

(d)

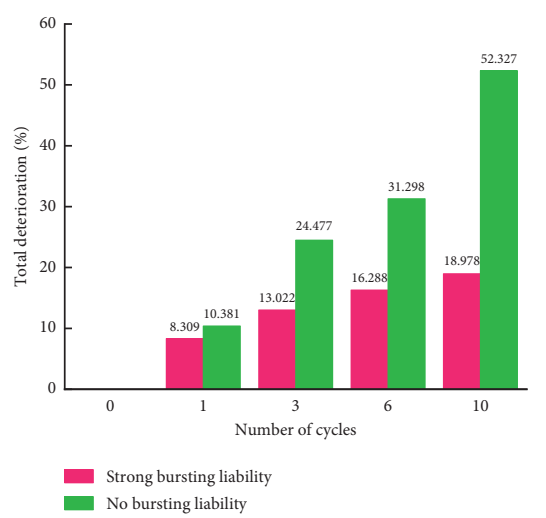

(b)

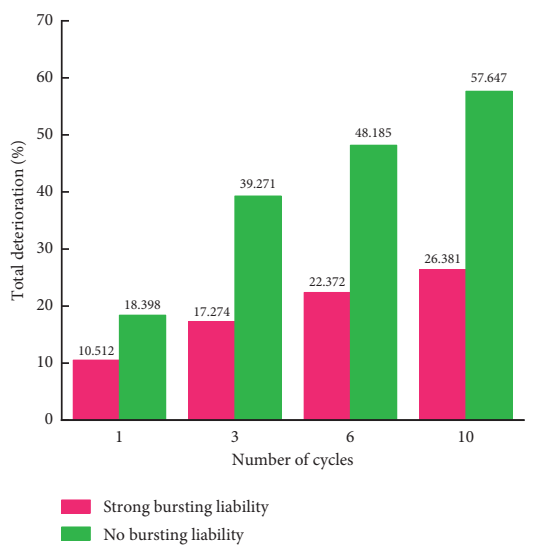

(e)

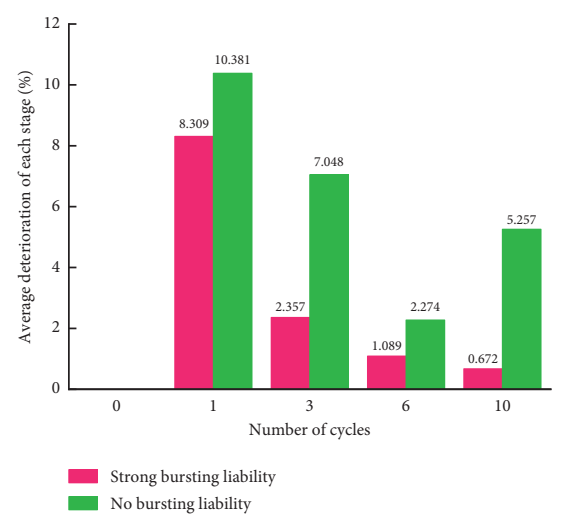

(c)

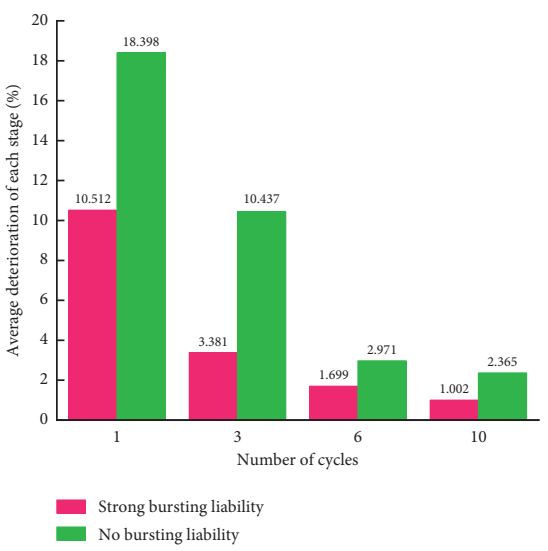

(f)

Figure 8: Continued. 


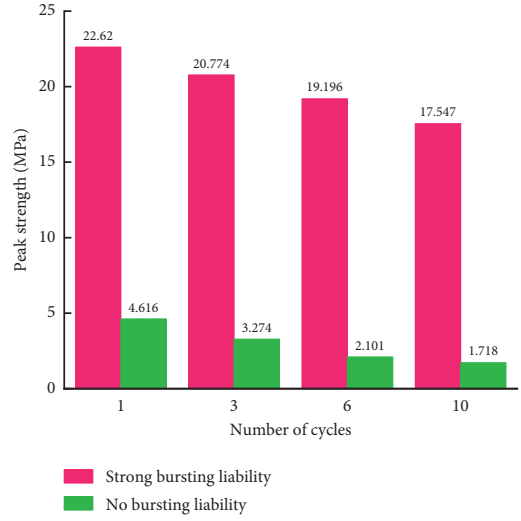

(g)

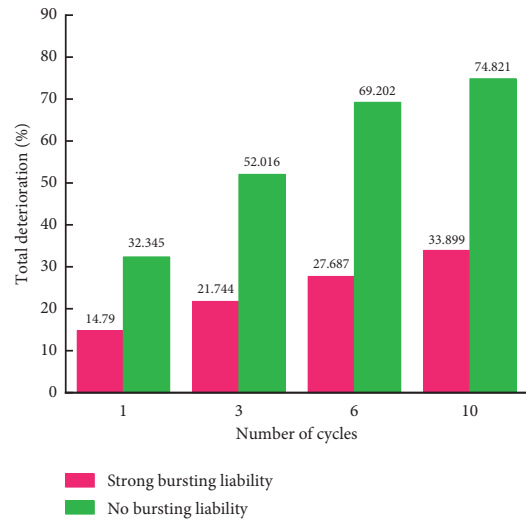

(h)

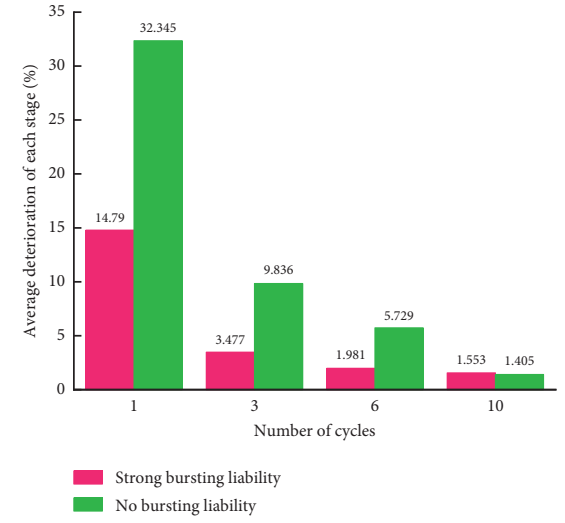

(i)

Figure 8: Uniaxial compressive strength and its deterioration of coal samples with different bursting liabilities: (a)-(c) $\mathrm{pH}=7$; (d) - (f) $\mathrm{pH}=9$; (g) - (i) $\mathrm{pH}=4$.

TABLE 2: Uniaxial compressive strength and its deterioration of coal samples.

\begin{tabular}{|c|c|c|c|c|c|c|}
\hline $\mathrm{pH}$ & Types of coal samples & $\begin{array}{l}\text { Number of } \\
\text { cycles }\end{array}$ & $\begin{array}{l}\text { Peak strength } \\
(\mathrm{MPa})\end{array}$ & $\begin{array}{l}\text { Cycle } \\
\text { phase }\end{array}$ & $\begin{array}{c}\text { Total deterioration } \\
(\%)\end{array}$ & $\begin{array}{c}\text { Average deterioration of each stage } \\
(\%)\end{array}$ \\
\hline \multirow{10}{*}{7} & \multirow{5}{*}{$\begin{array}{c}\text { Strong bursting } \\
\text { liability }\end{array}$} & 0 & 26.546 & 0 & 0.000 & 0.000 \\
\hline & & 1 & 24.341 & 1 & 8.309 & 8.309 \\
\hline & & 3 & 23.089 & 2 & 13.022 & 2.357 \\
\hline & & 6 & 22.222 & 3 & 16.288 & 1.089 \\
\hline & & 10 & 21.508 & 4 & 18.978 & 0.672 \\
\hline & \multirow{5}{*}{ No bursting liability } & 0 & 6.823 & 0 & 0.000 & 0.000 \\
\hline & & 1 & 6.115 & 1 & 10.381 & 10.381 \\
\hline & & 3 & 5.153 & 2 & 24.477 & 7.048 \\
\hline & & 6 & 4.688 & 3 & 31.298 & 2.274 \\
\hline & & 10 & 3.253 & 4 & 52.327 & 5.257 \\
\hline \multirow{8}{*}{9} & \multirow{4}{*}{$\begin{array}{c}\text { Strong bursting } \\
\text { liability }\end{array}$} & 1 & 23.756 & 1 & 10.512 & 10.512 \\
\hline & & 3 & 21.961 & 2 & 17.274 & 3.381 \\
\hline & & 6 & 20.607 & 3 & 22.372 & 1.699 \\
\hline & & 10 & 19.543 & 4 & 26.381 & 1.002 \\
\hline & \multirow{4}{*}{ No bursting liability } & 1 & 5.568 & 1 & 18.398 & 18.398 \\
\hline & & 3 & 4.144 & 2 & 39.271 & 10.437 \\
\hline & & 6 & 3.535 & 3 & 48.185 & 2.971 \\
\hline & & 10 & 2.890 & 4 & 57.647 & 2.365 \\
\hline \multirow{8}{*}{4} & \multirow{4}{*}{$\begin{array}{c}\text { Strong bursting } \\
\text { liability }\end{array}$} & 1 & 22.620 & 1 & 14.790 & 14.790 \\
\hline & & 3 & 20.774 & 2 & 21.744 & 3.477 \\
\hline & & 6 & 19.196 & 3 & 27.687 & 1.981 \\
\hline & & 10 & 17.547 & 4 & 33.899 & 1.553 \\
\hline & \multirow{4}{*}{ No bursting liability } & 1 & 4.616 & 1 & 32.345 & 32.345 \\
\hline & & 3 & 3.274 & 2 & 52.016 & 9.836 \\
\hline & & 6 & 2.101 & 3 & 69.202 & 5.729 \\
\hline & & 10 & 1.718 & 4 & 74.821 & 1.405 \\
\hline
\end{tabular}

saturated. Group 0 was the original specimen without the dry-wetting cycle. Groups 1, 2, 3, and 4 were tested after 1, 3, 6 , and 10 dry-wetting cycles in soaking solution with $\mathrm{pH}=7$, respectively. Groups 5, 6, 7, and 8 were tested after 1, 3, 6, and 10 dry-wet cycles in soaking solution with $\mathrm{pH}=4$, respectively. Groups 9, 10, 11, and 12 were tested after 1, 3, 6, and 10 dry-wet cycles in soaking solution with $\mathrm{pH}=9$, respectively.

It can be seen from Table 3 that the tensile strength of coal decreases with the increase of dry-wet cycles. The deterioration degree is faster in the early stage and slower in the late stage (Figure 9). Under acidic and alkaline environment, the decrease amplitude of tensile strength of coal is obviously larger than that in neutral solution, which indicates that under the action of acid-base solution soaking, the easily soluble minerals in coal react with hydrogen ions and hydroxyl ions in solution obviously, resulting in pores and microcracks, leading to the rapid formation of cracks in coal and full penetration. Compared with the coal with strong bursting liability, the strength of the coal without bursting liability is lower, but the degradation degree is higher. 
TABle 3: Dynamic tensile strength and its deterioration of coal samples.

\begin{tabular}{|c|c|c|c|c|c|c|}
\hline $\mathrm{pH}$ & Types of coal samples & $\begin{array}{c}\text { Number of } \\
\text { cycles }\end{array}$ & $\begin{array}{c}\text { Peak strength } \\
(\mathrm{MPa})\end{array}$ & $\begin{array}{l}\text { Cycle } \\
\text { phase }\end{array}$ & $\begin{array}{c}\text { Total deterioration } \\
(\%)\end{array}$ & $\begin{array}{c}\text { Average deterioration of each stage } \\
(\%)\end{array}$ \\
\hline \multirow{10}{*}{7} & \multirow{5}{*}{$\begin{array}{l}\text { Strong bursting } \\
\text { liability }\end{array}$} & 0 & 2.807 & 0 & 0.000 & 0.000 \\
\hline & & 1 & 2.647 & 1 & 5.701 & 5.701 \\
\hline & & 3 & 2.550 & 2 & 9.145 & 1.722 \\
\hline & & 6 & 2.457 & 3 & 12.470 & 1.108 \\
\hline & & 10 & 2.387 & 4 & 14.964 & 0.624 \\
\hline & \multirow{5}{*}{ No bursting liability } & 0 & 1.783 & 0 & 0.000 & 0.000 \\
\hline & & 1 & 1.617 & 1 & 9.346 & 9.346 \\
\hline & & 3 & 1.503 & 2 & 15.701 & 3.178 \\
\hline & & 6 & 1.407 & 3 & 21.121 & 1.807 \\
\hline & & 10 & 1.343 & 4 & 24.673 & 0.888 \\
\hline \multirow{8}{*}{9} & \multirow{4}{*}{$\begin{array}{l}\text { Strong bursting } \\
\text { liability }\end{array}$} & 1 & 2.550 & 1 & 9.145 & 10.512 \\
\hline & & 3 & 2.390 & 2 & 14.846 & 2.850 \\
\hline & & 6 & 2.285 & 3 & 18.575 & 1.243 \\
\hline & & 10 & 2.180 & 4 & 22.328 & 0.938 \\
\hline & \multirow{4}{*}{ No bursting liability } & 1 & 1.684 & 1 & 5.570 & 18.398 \\
\hline & & 3 & 1.514 & 2 & 15.103 & 4.766 \\
\hline & & 6 & 1.384 & 3 & 22.411 & 2.436 \\
\hline & & 10 & 1.300 & 4 & 27.084 & 1.168 \\
\hline \multirow{8}{*}{4} & \multirow{4}{*}{$\begin{array}{l}\text { Strong bursting } \\
\text { liability }\end{array}$} & 1 & 2.484 & 1 & 11.508 & 14.790 \\
\hline & & 3 & 2.254 & 2 & 19.691 & 4.091 \\
\hline & & 6 & 2.110 & 3 & 24.810 & 1.706 \\
\hline & & 10 & 2.021 & 4 & 28.005 & 0.799 \\
\hline & \multirow{4}{*}{ No bursting liability } & 1 & 1.573 & 1 & 11.776 & 32.345 \\
\hline & & 3 & 1.319 & 2 & 26.056 & 7.140 \\
\hline & & 6 & 1.154 & 3 & 35.290 & 3.078 \\
\hline & & 10 & 1.042 & 4 & 41.589 & 1.575 \\
\hline
\end{tabular}

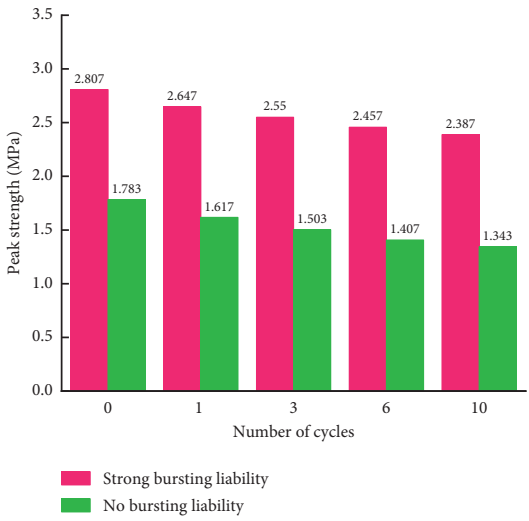

(a)

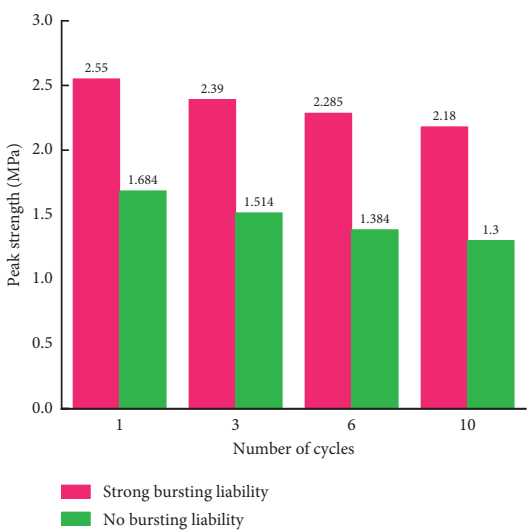

(d)

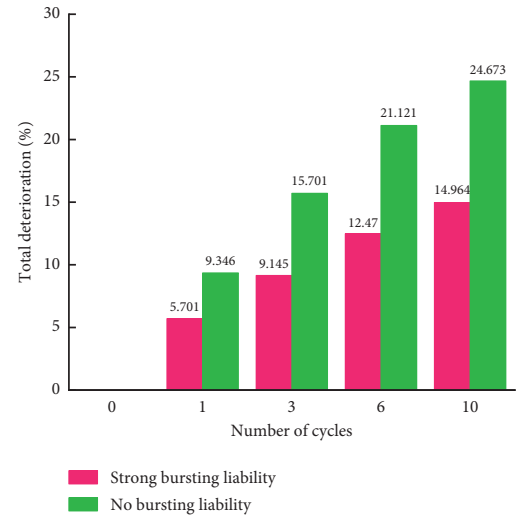

(b)

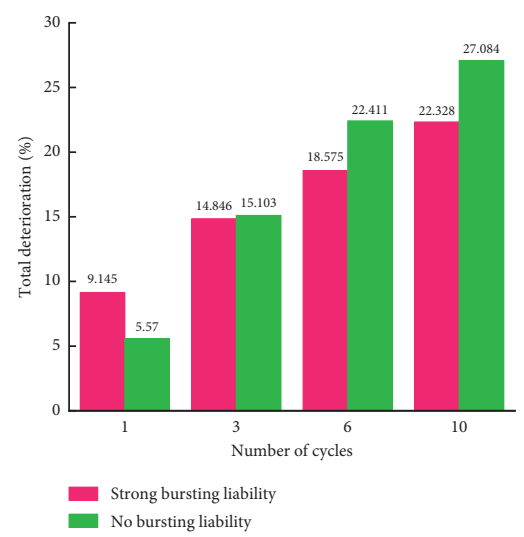

(e)

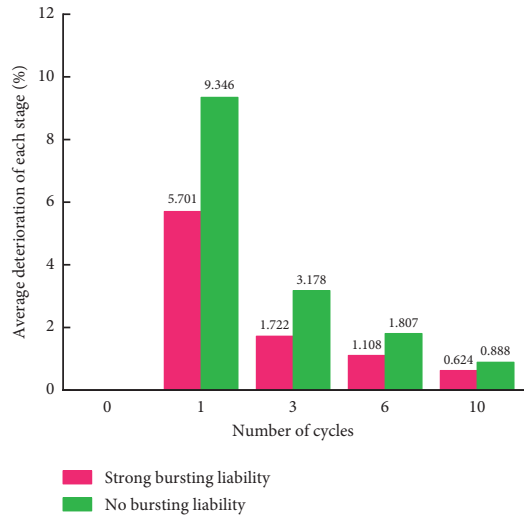

(c)

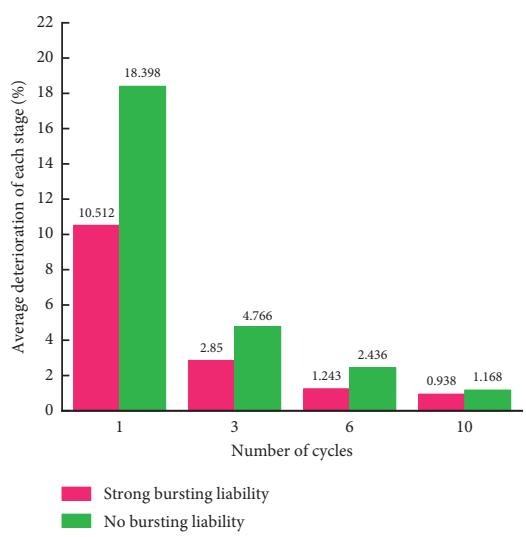

(f)

Figure 9: Continued. 


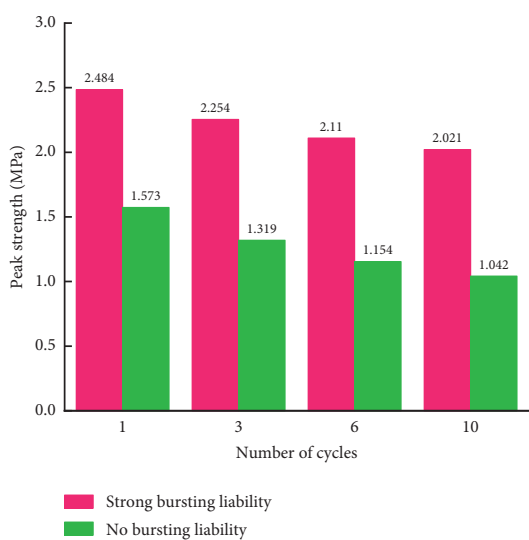

(g)

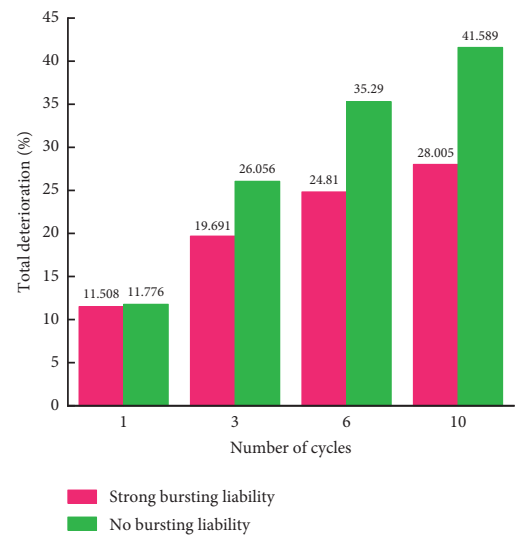

(h)

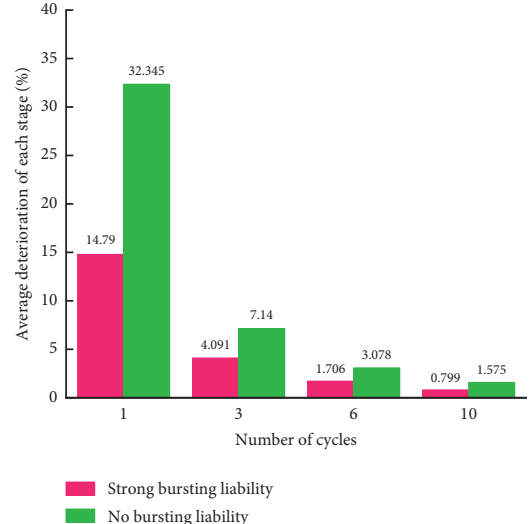

(i)

Figure 9: Dynamic tensile strength and its deterioration of coal samples with different bursting liabilities: (a) $-(\mathrm{c}) \mathrm{pH}=7$; (d) $-(\mathrm{f}) \mathrm{pH}=9$; (g) $-(\mathrm{i}) \mathrm{pH}=4$.

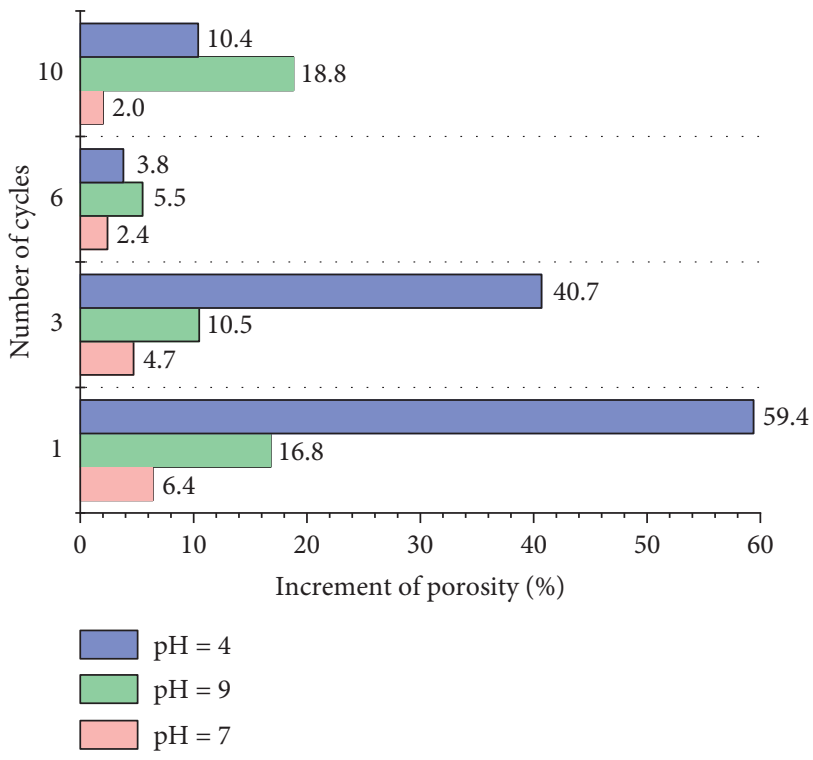

(a)

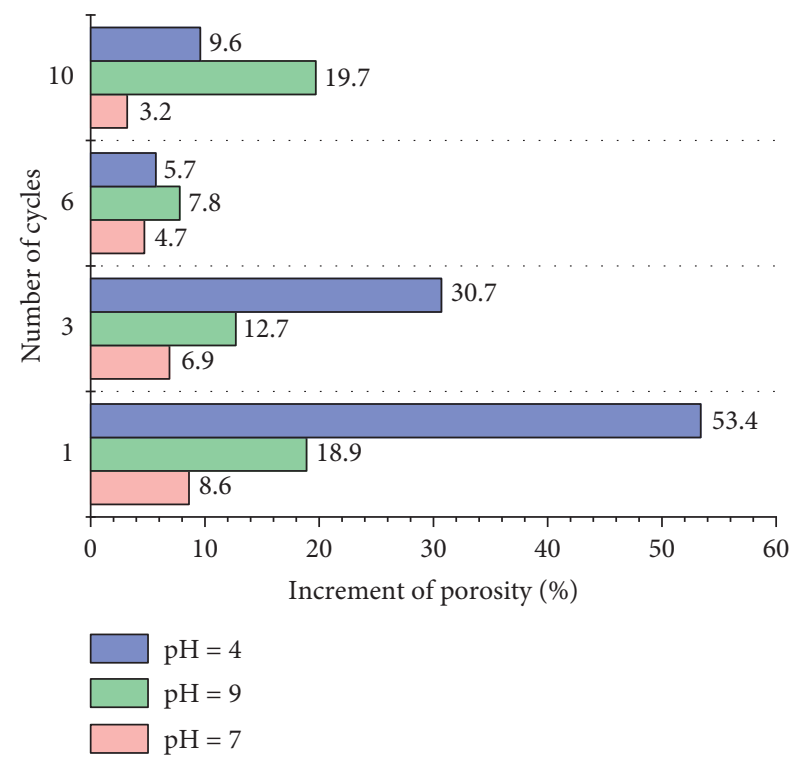

(b)

FIGURE 10: Incremental change of porosity of coal samples under different cycles in acid-base environment: (a) strong bursting liability; (b) no bursting liability.

3.3. Acid and Alkaline Environment on Porosity Characteristics of Bursting Liability Coal. Due to the complex structural plane and the diversity of mineral composition, the failure mechanism of rock under stress, physical, and chemical action is far from clear. After the action of hydrochemical solution, the internal microstructure of rock mass changes, which makes its physical and mechanical properties worse and threatens the long-term stability of rock engineering. Porosity has an important influence on the strength of rock. A series of complex physical and chemical interactions take place between the minerals of coal in chemical solution and the reaction particles (e.g., $\mathrm{H}^{+}$) in solution. It will lead to coal dissolution, which change the porosity of coal. Due to the reaction-migration and other physical and chemical processes after water erosion, some active minerals in coal undergo dissolution, adsorption, and other chemical processes. The dissolution reaction causes the minerals to dissolve, and the ionic substances generated migrate out of the coal to form voids. The adsorption results in a large number of particles covering the mineral surface of coal and blocking the pore channels in the coal. The final result of this reaction-migration-adsorption is that the pore structure inside the coal changes.

If the change of porosity of coal specimen during the action of aqueous solution is mainly caused by the dissolution and migration of constituent minerals in coal, then the change of porosity of coal specimen can be expressed by the following formula:

$$
\Delta \varphi=\varphi-\varphi_{0}=\sum_{i=1} \varphi_{i},
$$

where $\varphi$ is the porosity, $\varphi_{0}$ is the initial porosity, and $i$ refers to various minerals. 
Incremental porosity of coal in each stage can be calculated by formula (4), as shown in Figure 10. It can be concluded that the porosity of minerals decreases linearly in stages 1,2 , and 3 . In stage 4 , however, the increase in porosity begins to ease down due to the decrease in the dissolution rate of minerals. Porosity increment in acidic environment is much larger than that in alkaline and neutral environment. Porosity increment in alkaline environment is slightly larger than that in neutral environment, indicating that acidic environment is the most effective way to dissolve cements. Porosity increment of strongly bursting liability coal in acidic environment is initially greater than that of no bursting liability coal, while it is opposite in alkaline environment. It indicates that strong bursting liability coal is more sensitive to acidic environment, while no bursting liability coal is more sensitive to alkaline environment.

\section{Conclusions}

(a) The strong bursting liability coal shows scaly and mylonitic microstructure; however, the weak bursting liability coal shows a sheet-like and intergranular porous structure. The no bursting liability coal shows shell-like and porous microstructure. The surface micromorphology and structure characteristics of coal samples with different bursting liabilities are representative, which can be used as an auxiliary basis to determine the bursting liability of coal seam. In addition, the microstructure of coal with strong bursting liability is characterized by mylonitic, fragmentary, and brecciated structure, and the microstructure is diverse and complex. However, the microstructure of no bursting liability coal is single and uniform.

(b) The morphological characteristics and distribution of microfissures in coal are related to the bursting liability of coal. Coal with strong bursting liability shows tensile, compressive, and shear cracks produced by tectonic action, and the distribution of cracks is complicated. The development of fissures is greatly affected by the degree of coal metamorphism, organic components, minerals, and other factors.

(c) The degradation in acid environment is significantly greater than that in neutral and alkaline environment. In the saturated state, the deterioration degree of coal increases obviously, which is due to the existence of water in the coal rock, resulting in the sharp decrease of coal strength. Under acidic and alkaline environment, the decrease amplitude of tensile strength of coal is obviously larger than that in neutral solution, which indicates that under the action of acid-base solution soaking, the easily soluble minerals in coal react with hydrogen ions and hydroxyl ions in solution obviously.

(d) Porosity increment in acidic environment is much larger than that in alkaline and neutral environment. Porosity increment in alkaline environment is slightly larger than that in neutral environment, indicating that acidic environment is the most effective way to dissolve cements. Porosity increment of strongly bursting liability coal in acidic environment is initially greater than that of no bursting liability coal, while it is opposite in alkaline environment. It indicates that strong bursting liability coal is more sensitive to acidic environment, while no bursting liability coal is more sensitive to alkaline environment.

\section{Data Availability}

The data used to support the findings of this study are available from the corresponding author upon request.

\section{Conflicts of Interest}

The authors declare that there are no conflicts of interest.

\section{Acknowledgments}

This work was financially supported by the Science and Technology Project of China Coal Technology and Engineering Group Energy Development Co., Ltd. (2020QN02), the Fundamental Research Funds for the Universities of Henan Province (NSFRF200332), Key Research and Development and Promotion of Special (Science and Technology) Project of Henan Province (212102310379), and the Key Scientific Research Project Fund of Colleges and Universities of Henan Province (21A610005 and 20B440001). The support is greatly appreciated.

\section{References}

[1] M. N. Lamberson and R. M. Bustin, "Coalbed methane characteristics of gates formation coals, northeastern British columbia: effect of maceral composition," Bulletin, vol. 77, no. 12, pp. 2062-2076, 1993.

[2] Y. Zhao, G.-F. Zhao, and Y. Jiang, "Experimental and numerical modelling investigation on fracturing in coal under impact loads," International Journal of Fracture, vol. 183, no. 1, pp. 63-80, 2013.

[3] S. B. Chen, Y. M. Zhu, T. Y. Liu et al., "Impact of the clear fracturing fluid on the adsorption properties of CBM," Journal of China Coal Society, vol. 34, no. 1, pp. 89-94, 2009.

[4] K. H. S. M. Sampath, M. S. A. Perera, P. G. Ranjith et al., " $\mathrm{CH}_{4} / \mathrm{CO}_{2}$ gas exchange and supercritical $\mathrm{CO}_{2}$ based hydraulic fracturing as $\mathrm{CBM}$ production-accelerating techniques: a review," Journal of $\mathrm{CO}_{2}$ Utilization, vol. 22, pp. 212-230, 2017.

[5] S. Petzet, B. Peplinski, and P. Cornel, "On wet chemical phosphorus recovery from sewage sludge ash by acidic or alkaline leaching and an optimized combination of both," Water Research, vol. 46, no. 12, pp. 3769-3780, 2012.

[6] F. Wang, N. Liang, and G. Li, "Damage and failure evolution mechanism for coal pillar dams affected by water immersion in underground reservoirs," Geofluids, vol. 2019, Article ID 2985691, 12 pages, 2019.

[7] C. Gonzatti, L. Zorzi, I. M. Agostini, J. A. Fiorentini, A. P. Viero, and R. P. Philipp, "In situ strength of coal bed based on the size effect study on the uniaxial compressive 
strength," International Journal of Mining Science and Technology, vol. 24, no. 6, pp. 747-754, 2014.

[8] A. H. Ibrahim, K. K. Choong, M. A. Megat Johari, S. I. Md Noor, N. L. Zainal, and K. S. Ariffin, "Effects of coal bottom ash on the compressive strength of portland cement mortar," Applied Mechanics and Materials, vol. 802, no. 5, pp. 149-154, 2015.

[9] S. Gong, Z. Wang, L. Zhou, and W. Wang, "Experimental investigation on the tensile and fracture properties of burstprone coal under quasistatic condition," Shock and Vibration, vol. 2021, no. 1, 13 pages, Article ID 5593376, 2021.

[10] P. Guo, J. Gu, S. Yi, J. Wang, and Z. Ding, "Effect of cyclic wetting-drying on tensile mechanical behavior and microstructure of clay-bearing sandstone," International Journal of Coal Science \& Technology, vol. 2, pp. 1-13, 2021.

[11] H. Song, Y. Zhao, J. Wang, and Y. Jiang, "Experimental investigation of microstructure-related scale effect on tensile failure of coal," Natural Resources Research, vol. 30, pp. 1-16, 2020.

[12] Y. Yao and D. Liu, "Effects of igneous intrusions on coal petrology, pore-fracture and coalbed methane characteristics in Hongyang, Handan and Huaibei coalfields, North China," International Journal of Coal Geology, vol. 96-97, pp. 72-81, 2012.

[13] Y. L. Wei, C. H. Yang, Y. T. Guo et al., "Experimental investigation on deformation and fracture characteristics of brittle shale with natural cracks under uniaxial cyclic loading," Rock and Soil Mechanics, vol. 36, no. 6, pp. 1649-1658, 2015.

[14] A. Chi and L. Yuwei, "The model for calculating elastic modulus and Poisson's ratio of coal body," The Open Fuels \& Energy Science Journal, vol. 6, no. 1, pp. 36-43, 2013.

[15] M. Behrestaghi, K. S. Rao, and T. Ramamurthy, "Engineering geological and geotechnical responses of schistose rocks from dam project areas in India," Engineering Geology, vol. 44, no. 1, pp. 183-201, 1996.

[16] V. L. Shkuratnik, Y. L. Filimonov, and S. V. Kuchurin, "Regularities of acoustic emission in coal samples under triaxial compression," Journal of Mining Science, vol. 41, no. 1, pp. 44-52, 2005.

[17] W. Wang, T. Liu, J. Lu et al., "Experimental study of influence of water-rock chemical interaction on mechanical characteristics of sandstone," Chinese Journal of Rock Mechanics and Engineering, vol. 31, pp. 3607-3617, 2012.

[18] M. C. Westhoff, T. A. Bogaard, and H. H. G. Savenije, "Quantifying the effect of in-stream rock clasts on the retardation of heat along a stream," Advances in Water Resources, vol. 33, no. 11, pp. 1417-1425, 2010.

[19] T. Dewers and A. Hajash, "Rate laws for water-assisted compaction and stress-induced water-rock interaction in sandstones," Journal of Geophysical Research Solid Earth, vol. 100, no. 7, pp. 13093-13112, 1995.

[20] P. A. Rebinder, L. A. Schreiner, and K. F. Zhigach, Hardness Reducers In Drilling: A Physico-Chemical Method of Facilitating Mechanical Destruction of Rocks During Drilling, CSIRO, Melboune, Australia, 1944.

[21] L. J. Feucht and J. M. Logan, "Effects of chemically active solutions on shearing behavior of a sandstone," Tectonophysics, vol. 175, no. 1-3, pp. 159-176, 1990.

[22] X. T. Feng, S. J. Li, and S. L. Chen, "Effect of water chemical corrosion on strength and cracking characteristics of rocks-a review," Key Engineering Materials, vol. 261, 2004.

[23] X.-T. Feng, S. Chen, and H. Zhou, "Real-time computerized tomography (CT) experiments on sandstone damage evolution during triaxial compression with chemical corrosion,"
International Journal of Rock Mechanics and Mining Sciences, vol. 41, no. 2, pp. 181-192, 2004.

[24] Y. X. Zhang, J. C. Sun, X. Chen et al., "Characteristics and preliminary analyses of the formation of $\mathrm{pH}$ in shallow groundwater in the Pearl River Delta," Hydrogeology and Engineering Geology, vol. 38, no. 1, pp. 16-21, 2011. 